$\S=-1$

\title{
The Effects of Air Pollution on Socio - Economic Activities in Sokoto State, Nigeria
}

\author{
Muhammad Bello Muhammad ${ }^{1}$, Rahimah Abdul Aziz ${ }^{2}$, Vivien W.C. Yew ${ }^{3}$ \\ ${ }^{1,2,3}$ Social, Environment and Developmental Sustainability Research Centre, Faculty of Social Sciences and Humanities, Universiti Ke- \\ bangsaan Malaysia \\ *Corresponding author E-mail: ibnmuhd80@siswa.ukm.edu.my
}

\begin{abstract}
The main aim of the paper is to look into the effects of air pollution on socio - economic activities in Sokoto state, Nigeria, to sensitize the populace on the dangers associated with environmental pollution and possibly profer solutions to the problems. Secondary data was used to systematically review the literature through narrative method. Talcott Parsons 'AGIL' schema was used in this paper. The findings revealed some pollutants that were identified and widely associated with air pollution, especially with emissions from industrial activities, auto mobiles and other sources of pollutants that causes harm to both man and his environment. The findings also revealed that Sokoto Cement Company is supposed to be a source of development to Kalambaina community, through job creation, providing cheaper building materials and other social amenities, however, it has negatively impacted the community to a large extent by endangering the health of the populace, thereby, stagnating their socio-economic development. Recommendations were made that the government should create policies that will make the Company responsible for the damages caused by pollution to the host community.They should provide tenure employment, social amenities and also be made to implement environment friendly policies that will limit the pollution caused by the activities of the Company.
\end{abstract}

Keywords: Air pollution; Pollutants; Environment; Socio-economic activities; Nigeria.

\section{Introduction}

Air is one of the major components that man needs to survive. Therefore the quality of air we breathe has a greater contribution to the comfort of man's existence on earth. And as such, the source of air and its composition are very important in this paper. It does not matter who you are, where you live or the state of your health, the quality of air you breathe each day affects you.(1) A lot of chemicals and gases are generated in cement production. Precautionary measures against inhalation of those chemicals and gases are generally poor or non-existent owing to lack of resources by the management of the industries and ignorance in the part of the public(2).

Pollution is the presence of harmful substances in the environment at levels greater than it should be. Air pollution is caused by any undesirable substance, which enters the atmosphere. Air pollution is a major problem in modern society. Even though air pollution is usually a greater problem in cities, pollutants contaminate air anywhere.

These substances include various gases and tiny particles, or particulates that can harm human health and damage the environment. The major hazardous pollutants in urban cities are carbon monoxide, nitric oxide, sulphur dioxide, particulate matter and smog. They may be gases, liquids, or solids. Many pollutants are emitted into the air as a result of human activities causing harm to the environment.

\section{Literature Review}

Industrialization as a process cannot be understood without referring to people living in societies. Therefore, there is a close connection between society and its environment on the one hand and industries on the other. People exploit their social and physical environment in order to survive and enhance their lives. Once an industry is established in a place to manufacture certain goods, it generate changes on the socio-economic life of the people living in that area by providing employment and other business opportunities. On the other hand the activities of the industries also brings negative changes to the environment which affects the socio-economic development of the community, such as housing and pollution problems which includes air, water and land pollution with adverse effects on human, animal health, and other scenic resources(3-11).

Any substance in the air that can cause harm to human and the environment is known as air pollutant. Pollutants can be in the form of solid particles, liquid droplets, or gases. In addition, they may be natural or man-made.

In terms of the damage to plants caused by air pollution, forests could be damaged and agricultural area recording poor growth and yield. This could be caused by the sulphur dioxide (SO2) and hydrogen fluoride (HF) from stationary sources. Plant damage could also result from mobile sources including automobiles. An increase of UV radiation would be expected to affect crops. A number of economically important species of plants, such as rice, depend on cyanobacteria residing on their roots for the retention of 
nitrogen. Cyanobacteria are sensitive to UV light and they would be affected by its increase(12). Also in Nigeria, in addition to desertification in the North and the hazards of oil producing activities in the Niger - Delta, soil erosion, deforestation and overgrazing are adversely affecting productivity in the farming; forestry and livestock sectors, thereby slowing overall economic growth in the country. In Sokoto State for example, over the years, successive district heads have not shown concern over the implications of the activities of the cement company especially from the emissions which causes air pollution on their populace, rather they are being accussed of corruption by their wards due to the personal benefits they derive from the company; they deny the masses of their rights and surpress any agitation from them. As a result, these and other factors have affected the socio-economic activities of the community.

Air pollution is a major environmental health threat to humans, especially for children in whom respiratory function is still developing(13). Exposure to several air pollutants, e.g., sulfur dioxide, nitrogen oxides, and particulate matter, is a known risk factor for acute and chronic respiratory infections (14-16) as well as other diseases including myocardial infection, ischemic stroke, and cardiopulmonary disease(17).

In recent decades the world has witnessed serious environmental disasters much of which resulted from industrialization and urbanization which has become a global phenomenon. Even though there has been a United Nations declaration on human environment since 1972 in Stockholms, the problem still persist. Environment is one of the critical aspects of human life and a factor that determines the level of development in a given area.

\subsection{Effects of Pollutants on the Life of Industrial Communities of Nigeria}

Atmospheric pollution is also gradually becoming a serious menace in Nigerian cities. Inefficient energy combustion in the transportation system generate high levels of localized air pollution, especially in the metropolitan areas. The recent increase in the importation of second-hand cars and the widespread adoption of the single-engine, "okada" motor-cycles for ferrying passengers all over most of Nigerian cities have accentuated the general level of air pollution.

Indeed, motor vehicles produce more air pollution than any other single human activity. Nearly 50 percent of global carbon monoxide, hydrocarbon, and nitrogen oxide emission from fossil fuel combustion come from gasoline - and diesel powered engines. In city centers, especially on highly congested streets, traffic can be responsible for as much as 90 to $95 \%$ of the ambient carbon monoxide levels, 80 to $90 \%$ of the nitrogen oxides and hydrocarbons, and a large portion of the particulates, posing a significant threat to human health and natural resources(18).

Heavy reliance on biomass materials as the main energy source for domestic needs, especially by the poor has also been identified, among other things, as partly responsible for a variety of health problems particularly among women. Industrial energy use contributes to the overall level of air pollution. In this regard, the gas flaring in the oil-producing regions of the country represent perhaps the most pernicious of atmosphere pollution in the country In particular, they have heightened the level of airborne emissions of such pollutants as sulphur dioxide, carbon monoxide and nitrogen oxides, all of which pose serious health hazards in urban areas. It is claimed that Nigeria's carbon dioxide emissions from industrial processes, estimated at 96513 million metric tons in 1992 was the highest in sub-Saharan Africa, excluding the Republic of South Africa. The emission from flared gas alone accounted for more than one half of this figure(19).

Also, the effects of particulate matter on human health has been noted by several scholars, for instance $(20,21)$ asserted that high rates of respiratory diseases occassioned by increased particulate matter concentrations were experienced by residents of most urban areas. Specifically, $(22,23)$ noted that residents of refinery road, commercial areas, traffic-clogged areas and high-density residential areas in the Warri metropolis were the most affected, with over $15 \%$ of the cases recorded among infants and children in Benin city, Ibadan, Kano and Port Harcourt, etc.

Cement-based materials, such as concrete and mortars, are used in extremely large amounts. For instance, in 2009 concrete production was superior to 10 billion tons. Cement plays an important role in terms of economic and social relevance since it is fundamental to build and improve infrastructure. On the other hand, this industry is also a heavy polluter. Cement production releases 5$6 \%$ of all carbon dioxide generated by human activities, accounting for about $4 \%$ of global warming. It can release huge amounts of persistent organic pollutants, such as dioxins and heavy metals and particles. Energy consumption is also considerable. Cement production use approximately $0.6 \%$ of all energy produced in the United States(24).

In Tanzania Yhdego(25) in his study found that diseases such as chest pain, cough, and eye problems in the villages affected by cement dust were likely to be due to cement dust.(26) in their study on Ambient air quality and health hazards near mini cement plants, found that people of cement dust zone were badly affected by respiratory problems, and gastrointestinal diseases,(27), in India, in their study on health risks for population living in the neighborhood of a cement factory also found that cement dust is not only the major cause of environmental pollution in the study area but also a threat to health of local residents.

Oguntoke, Awanu, \& Annegarn (28) in their study on Impact of cement factory operations on air quality and human health in Ewekoro Local Government Area, South-Western Nigeria, found that the health profile of the factory workers and some residents of neighbouring communities showed high levels of respiratory and skin infections due to significantly higher particulate matter within and around the production plant. Earlier studies by(29-32) and focused on cement factory workers or measured respirable dust concentration to which the workers were exposed to within the factory. Also, studies have shown that cement dust exposure in the factory, or in the community led to higher prevalence of illnesses such as cough, phlegm, shortness of breath with wheeze, chest pain, skin lesions and conjunctivitis. The prevalence of illnesses is as a result of chronic cement dust exposure and the nature of cement which is highly alkaline; (PH 12-13). As a result, wet cement is strongly caustic and can easily cause severe skin burns if not promptly washed off with water. Similarly, dry cement powder in contact with mucous membranes can cause severe eye or respiratory irritation (33).

\subsection{Theoretical Framework}

\section{The Functionalist Perspective}

An accepted premise of the functionalist position is that no human custom, institution, or set of behaviour exists in vaccum; there must always be an interplay between the component elements of a social system (including the environment), and a continuing interdependence between them is created on many different levels.(34). Structural - functionalism seeks to describe the social system in terms of structures, mechanisms, processes, and functions and to explain why a given structure rather than another contributes to the satisfaction of a given functional requisite at a given time. The functionalist draws mainly upon the ideas of the pioneer sociologists - Auguste Comte, Herbert Spencer, and Emile Durkheim. And one of the features of a system stressed by functionalists is its tendency toward equilibrium, or balance, among its parts and among the forces operating on it.

\section{Human-Environment Interactions: The Functionalist Perspec-} tive

The functionalist perspective has the following draw backs. It has difficulty in dealing with history and processes of change, has the tendency to exaggerate consensus, integration, and stability while 
disregarding conflict, dissent and instability it is still a useful tool for describing society and identifying its structural part and the functions of these parts. Functionalism for instance, provides a "big picture" of the whole social life, particularly as it finds expressions in patterned, recurrent behaviour and institutions.

The functionalist perspective can be used to analyse various aspects of the human-environment interaction. The functionalists approach the ecological environment by examining the interconnections between the various parts composing the ecosystem.(35) Functionalists see the ecosystem as exhibiting a tendency toward equilibrium; in which its components maintain a delicate balanced relationship with one another. Functionalists stress that our survival depends on our ability to maintain a precarious balance among the living and nonliving components comprising the biosphere(36).

Sociologists have tried to understand and explain all aspects of human life, using different theoretical perspectives. For this paper, in order to address the issue of air pollution; Parsons 'AGIL' schema will be of relevance because it has shown how societal problems can be resolved especially those affecting the structures and institutions of the society. The main concern of the functionalist school of thought is on large-scale social structures and institutions of society, their interrelatedness, interdependence, functions, as well as their constraining effects on actors(37).

The fundamental assumption of the functionalists' perspective is the analogy between human body and society. The entire society is viewed as an organism with different parts like lungs, brain, heart etc., which must function for the survival of the entire system. If any part is dysfunctional, it is likely to affect the entire system. Therefore, sociologists ought to study social institutions and structures that make up the society in terms of their interrelatedness and interdependence. Thus, the study of the parts is done in terms of the function each performs for the maintenance and survival of the entire social system. However, Functionalists believe that certain degree of order and stability are essential for the survival of social system; and the key to this explanation, according to them, is shared values. In other words, value consensus forms the fundamental integrating principle in society because it provides the foundation for cooperation hence produce common goals(38)

Parson(39) viewed society as a system. He argues that, for any system to survive, certain prerequisites must be met. These are the imperatives of Adaptation; Goal attainment; and Integration; Latency. In other words, if society is to maintain order or stability in terms of development it must solve the four fundamental problems or functional prerequisites. For example, industrialization and urbanization has come with a lot of developmental changes in terms of production process and this has greatly affected the environment in so many dimensions.

Adaptation: means the system must adjust to its environment and adjust the environment to its own needs. At a minimum, food and shelter must be provided to meet the physical needs of members. Society's failure to adapt, may pose a threat to order and stability. For example, in order to meet the need for shelter for its growing population, societies will have to produce more building materials such as cement. Limestone is one of the raw materials for manufacturing cement. The discovery of limestone in Sokoto State has facilitated the establishment of Sokoto Cement Company which is expected to bring development to the people of the state, yet, in the process, problems associated with air pollution such as health hazards, low crop yields, contaminated weeds for grazing, land degradation etc were created as a result of the excavations and smog emitted by the factory. The environment provides the resources essential for life; these include air, water, and materials used to create shelter, and other needed products. If human societies exhaust these resources, for example by polluting the air or water supply (40) argued the consequences can be dire. Thus, in order to attain relative order and stability, there has to be alternative ways of minimizing the extent of air pollution which have adverse effect on all aspects of human life.
Goal attainment: This refers to the need for the society to define and achieve its goals. Parsons argued, the goal of any system is to survive into the future. This can be used to explain the need for sustainable use of resources that could not only serve the need for present generations, but also that of future generations, which are both necessary for societal survival, growth and expansion. On this basis, it has become necessary for government to make, enforce and monitor environmental friendly policies that regulate the activities of the cement company.

Integration:This is one of the problems that society must solve in order to survive. Social institutions perform different and sometimes similar functions, which contribute to the survival of the whole system, in the process of performing these functions, each system must seeks to regulate the interrelationship of its component parts. There is need for coordination and mutual adjustment of parts of a social system by defining standard norms governing relations between individuals and institutions so as to avoid chaos and disorder. In this regard, there should be a symbiotic relationship between the company and the host community, in as the company benefits from the production of cement; they should give back to the host community by providing basic social amenities; such as bore holes, schools, clinics, etc.

Latency or Pattern maintenance: which means the need for the system to furnish, maintains, and renews the cultural patterns that create and sustain individual motivation. Here the Company should have good rapport with the host community by motivating individuals, so that, they both understands the benefit and relevance of each other.

Parsons 'AGIL' schema is of relevance to this study because it has shown how societal problems can be resolved especially those affecting the structures and institutions of the society through harmonious relationship between Sokoto Cement Company and the communities involved by taking into consideration the implications of air pollution from the company on the lives of the people, likewise the people recognising the importance of the company to thier development. The major limitation to the theory is the vicious nature of capitalism which makes the Cement Company to always maximize profit and minimize cost in return neglecting the needs of the people in the communities which will negate the harmonious relationship in the society. Thus, consensus and equilibrium will be hard to attain as postulated by Functionalism.

\section{Methodology}

Secondary data was used to systematically review relevant scholarly literature through mapping and forming a narrative method. In order to address the issue of air pollution, Functionalist paradigm was used in this paper, in which Talcott Parsons 'AGIL' schema was relevant because it had shown how societal problems can be resolved especially those affecting the structures and institutions of the society.

\section{Results and Findings}

The findings revealed that, although various pollutants have been identified by researchers in Environmental Sociology, some pollutants were, however, identified and widely associated with air pollution, especially with emissions from industrial activities, auto mobiles and other sources of pollutants that causes harm to both man and his environment. These pollutants include Sulphur dioxide, Particulate matter, Carbon monoxide, Carbon dioxide, etc. The findings also revealed that, although Sokoto Cement Company is supposed to be a source of development to Kalambaina community through job creation, providing cheaper building materials and other social amenities, however, it has negatively impacted the community to a large extent by endangering the health 
of the populace, thereby, stagnating their socio-economic development (Clinic records, 2014).

\section{Conclusion}

Conventional air pollution has also been linked to decreases of lung function, increase of heart attacks, respiratory diseases, cancer, asthma, and other health effects. Pollution also creates odour and smog, diminishing the protective ozone layer. Environmental health effects, climate change and ambient air pollution, faced by people living in Some States in Nigeria can only be reduced if the government for example - create and enforce environmental friendly policies that will protect communities' interest and make companies to implement these policies so as to better their living condition. Companies should provide social amenities like boreholes, health centres, provision of jobs for the host community, etc. These will make the communities to have a sense of belonging and will compensate the damages done to the communities.

\section{References}

[1] 1. Obi E, Osang J, Ewona I, Udoimuk A, Kamgba F. Environmental health Effect and Air Pollution from cigarette smokers in Cross River State, Nigeria. Iosr Journal Of Applied Physics (Iosr-Jap) E-Issn. 2013:2278-4861.

[2] Agyeman J, Bullard RD, Evans B. Exploring the nexus: Bringing together sustainability, environmental justice and equity. Space and polity. 2002;6(1):77-90.

[3] Abegglen JC. The Japanese Factory: Aspect of Its Social Organisation: Free Press; 1958

[4] Rasli AM, Qureshi MI, Isah-Chikaji A, Zaman K, Ahmad M. New toxics, race to the bottom and revised environmental Kuznets curve: The case of local and global pollutants. Renewable and Sustainable Energy Reviews. 2017.

[5] .Qureshi MI, Yusoff RM, Ahmed AR, Isa K, Imran A. Linking Quality of Work Life with Sustainable Manufacturing Performance. Advanced Science Letters. 2017;23(9):8232-5.

[6] Qureshi MI, Hassan MA, Hishan SS, Rasli AM, Zaman K. Dynamic linkages between sustainable tourism, energy, health and wealth: Evidence from top 80 international tourist destination cities in 37 countries. Journal of cleaner production. 2017;158:143-55.

[7] Qureshi MI, Rasli AM, Zaman K. Energy crisis, greenhouse gas emissions and sectoral growth reforms: Repairing the fabricated mosaic. Journal of Cleaner Production. 2016;112:3657-66.

[8] Qureshi MI, Awan U, Arshad Z, Rasli AM, Zaman K, Khan F. Dynamic linkages among energy consumption, air pollution, greenhouse gas emissions and agricultural production in Pakistan: sustainable agriculture key to policy success. Natural Hazards. 2016;84(1):367-81.

[9] Qureshi MI, Rasli AM, Jusoh A, Kowang TO. Sustainability: A new manufacturing paradigm. 2015.

[10]. Qureshi MI, Rasli AM, Awan U, Ma J, Ali G, Alam A, et al. Environment and air pollution: health services bequeath to grotesque menace. Environmental Science and Pollution Research. 2015;22(5):3467-76

[11]. Qureshi MI, Khan NU, Rasli AM, Zaman K. The battle of health with environmental evils of Asian countries: promises to keep. Environmental Science and Pollution Research 2015;22(15):11708-15

[12]. Sinha RP, Klisch M, Häder D-P. Induction of a mycosporine-like amino acid (MAA) in the rice-field cyanobacterium Anabaena sp. by UV irradiation. Journal of Photochemistry and Photobiology B: Biology. 1999;52(1-3):59-64.

[13]. Liu L, Zhang J. Ambient air pollution and children's lung function in China. Environment international. 2009;35(1):178-86.

[14]. Kagawa J. Evaluation of biological significance of nitrogen oxides exposure. The Tokai journal of experimental and clinical medicine. 1985;10(4):348-53.

[15]. Balmes JR, Fine JM, Sheppard D. Symptomatic Bronchoconstriction after Short-Term Inhalation of Sulfur Dioxide1 2. Am Rev Respir Dis. 1987;136:1117-21.

[16].Kampa M, Castanas E. Human health effects of air pollution. Environmental pollution. 2008;151(2):362-7.
[17]. Organization WH. International statistical classification of diseases and related health problems: World Health Organization; 2004.

[18].Institute WR, Nature IUfCo, Resources N. Global biodiversity strategy: Guidelines for action to save, study, and use earth's biotic wealth sustainably and equitably: World Resources Inst; 1992.

[19]. Faiz A, Weaver CS, Walsh MP. Air pollution from motor vehicles: standards and technologies for controlling emissions: World Bank Publications; 1996.

[20]. Ossai E, Iniaghe G, Osakwe S, Agbaire P. Pollution Problems and Environmental Effects of Chemicals. Reading in General Studies: History and Philosophy of Science, Abraka General Studies Dept Pub. 1999:83-6.

[21]. Okecha SA. Pollution and conservation of Nigeria's environment: T'Afrique International Associates (WA); 2000.

[22].Efe S. Urban effects on precipitation amount, distribution and rainwater quality in Warri metropolis: $\mathrm{Ph}$. D. Thesis Department of Geography and Regional Planning, Delsu-Abraka; 2005.

[23].Efe S. Particulate pollution and its health implications in Warri Metropolis, Delta State, Nigeria. Env Anal. 2006;11:1339-51.

[24]. Rodrigues F, Joekes I. Cement industry: sustainability, challenges and perspectives. Environmental Chemistry Letters. 2011;9(2):15166.

[25]. Yhdego M. Epidemiology of industrial environmental health in Tanzania. Environment international. 1992;18(4):381-7.

[26]. Adak M, Adak S, Purohit K. Ambient air quality and health hazards near mini cement plants. Pollution Research. 2007;26(3):361.

[27]. Mehraj SS, Bhat G, Balkhi HM, Gul T. Health risks for population living in the neighborhood of a cement factory. African Journal of Environmental Science and Technology. 2013;7(12):1044-52.

[28]. Oguntoke O, Awanu AE, Annegarn HJ. Impact of cement factory operations on air quality and human health in Ewekoro Local Government Area, South-Western Nigeria. International journal of environmental studies. 2012;69(6):934-45.

[29]. Merenu I, Mojiminiyi F, Njoku C, Ibrahim M. The effect of chronic cement dust exposure on lung function of cement factory workers in Sokoto, Nigeria. African journal of biomedical research. 2007;10(2).

[30]. Oleru U. Pulmonary function and symptoms of Nigerian workers exposed to cement dust. Environmental research. 1984;33(2):379 85 .

[31]. Alakija W, Iyawe V, Jarikre L, Chiwuzie J. Ventilatory function of workers at Okpella cement factory in Nigeria. West African journal of medicine. 1990;9(3):187-92.

[32]. Huang CYYCC, Chiu HFCJF, Ko SJLYC. Effects of occupational dust exposure on the respiratory health of Portland cement workers. Journal of Toxicology and Environmental Health Part A 1996;49(6):581-8.

[33]. Hewlett P. Leas chemistry of cement and concrete. Ed BH. Oxford; 1998.

[34].Spencer RF. The nature and value of functionalism in anthropology: na; 1965.

[35]. Faia MA. Cultural materialism in the functionalist mode. American Sociological Review. 1989;54(4):658-60

[36]. Hughes M, Kroehler CJ, Vander Zanden JW. Sociology: the core: McGraw-Hill Companies; 1998.

[37]. Ritzer G, Stepnisky J. Contemporary sociological theory and its classical roots: The basics: SAGE Publications; 2017.

[38].Haralambos M, Holborn M, Heald R. Sociology: Themes and perspectives: HarperCollins Publishers; 2004.

[39].Parson T. The social system, Glencoe. The Free Press; 1951.

[40] . Schaefer RT. Encyclopedia of race, ethnicity, and society: Sage; 2008. 